\title{
As concepções de desenvolvimento humano nos objetivos da Educação Física na educação infantil no município de Criciúma, Santa Catarina
}

\author{
Bruna Carolini De Bona' \\ Diênifer Leal Mornes²
}

\section{RESUMO}

Este artigo tem por finalidade compreender as concepções de desenvolvimento humano que estão presentes nos objetivos da Educação Física na Educação Infantil nas instituições públicas de Criciúma. Como metodologia, se constitui de uma pesquisa de campo, em que quarenta e oito professores responderam à seguinte questão: qual o objetivo da Educação Física na Educação Infantil? Constatamos que 89,6\% dos professores entrevistados não planejam suas aulas de acordo com a teoria histórico-cultural, base da formação humana, expressa nos documentos que regulamentam a Educação Física na Educação Infantil do município. E, portanto, possuem objetivos que não se articulam. Finalizamos indicando que a atividade principal da criança nesta etapa da Educação Básica é a atividade de jogo.

Palavras-chave: Objetivos. Educação física. Educação infantil.

1 Mestra em Educação. Professora do Curso de Licenciatura em Educação Física da Universidade do Extremo Sul Catarinense (UNESC). Criciúma/Santa Catarina, Brasil. E-mail: bcb@unesc.net

2 Licenciada em Educação Física. Universidade do Extremo Sul Catarinense (UNESC). Criciúma/Santa Catarina, Brasil. E-mail: dieny_dlm@hotmail.com.

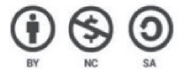

Este texto está publicado sob uma licença Creative Commons Atribuição NãoComercial-Compartilhalgual - CC BY NC AS

Mais detalhes em: https://br.creativecommons.org/licencas/ 
The conceptions of human development at the Physical Education objectives in child education in the city of Criciúma, Santa Catarina

\begin{abstract}
This article has as its purpose to understand the conceptions of human development that are present at the Physical Education objectives in Child Education in the public institutions of Criciúma. As a methodology, it consists of a field research, whereupon forty-eight teachers answered the following question: What is the objective of Physical Education in Child Education? We found that $89.6 \%$ of the interviewed teachers do not plan their classes according to the historical-cultural theory, expressed in the files that guide the Physical Education in the Child Education of the county, which generates a disarticulation with the objectives proposed in the teaching organization. We conclude by indicating that the main activity of the child in this stage of Basic Education is the game activity.
\end{abstract}

Keywords: Objectives. Physical education. Child education.

Las concepciones de desarrollo humano en los objetivos de Educación Física en la educación infantil en el municipio de Criciúma, Santa Catarina

\title{
RESUMEN
}

Este artículo tiene por finalidad comprender las concepciones de desarrollo humano que están presentes en los objetivos de Educación Física en la Educación Infantil en las instituciones públicas de Criciúma. Como metodología, se constituye una investigación de campo, donde cuarenta y ocho profesores respondieron a la siguiente cuestión: ¿cuál es el objetivo de la Educación Física en la Educación Infantil? Constatamos que 89,6\% de los profesores encuestados no planean sus clases de acuerdo con la teoría históricocultural, expresa en los documentos que orientan a la Educación Física en la Educación Infantil del municipio, lo que genera una desarticulación con los objetivos propuestos en la organización de la enseñanza. Finalizamos indicando que la actividad principal del niño en esta etapa de la Educación Básica es la actividad de juego.

Palabras clave: Objetivos. Educación física. Educación infantil. 


\section{INTRODUÇÃO'}

A disciplina de Educação Física perpassou um processo de desenvolvimento lógico e histórico conturbado diante das demais áreas do magistério. Tomando para si características de cada tempo histórico, bem como suas organizações econômico-políticas, sofreu com rotulações da sociedade, por não ter um objeto de estudo esclarecido. Na atualidade, propaga a ideia do professor de Educação Física como professor 'rola bola' ${ }^{4}$.

Essas premissas englobam todos os níveis de ensino. Apontamos a Educação Infantil por ser a etapa que as crianças têm o primeiro contato com o conhecimento científico sistematizado. E segundo Leontiev (2014, p. 59) "a infância pré-escolar é o período da vida em que o mundo da realidade humana que cerca a criança abre-se cada vez mais para ela".

De acordo com Pasqualini (2006, p.14)

[...] a produção contemporânea sobre a Educação Infantil revela-se compromissada com uma perspectiva idealizada e naturalizante do desenvolvimento humano em geral e infantil em particular, não respondendo às demandas colocadas no cenário atual do segmento no que se refere ao plano pedagógico.

Diante desta afirmação, sentimos necessidade de realizar esta pesquisa para compreender qual é o objetivo da Educação Física na Educação Infantil no Município de Criciúma. No intuito de conhecer as concepções de desenvolvimento humano que dão base aos objetivos de Educação Física citados pelos professores, para analisarmos como ocorrem as suas aulas na Educação Infantil.

Segundo a LDB (9.394), promulgada em 20 de dezembro de 1996, a Educação Física, no Artigo 26 - $\S 3^{\circ}$ - "integrada à proposta pedagógica da escola, é componente curricular da Educação Básica ${ }^{5}$, ajustando-se às faixas etárias e às condições da população escolar" (BRASIL, 1996).

O governo do Estado de Santa Catarina com a Lei complementar $n^{\circ} 170$, de 07 de agosto de 1998, em seu Capítulo III - Art.32, sanciona que "na educação infantil, o ensino da arte e a educação física são componentes curriculares obrigatórios, ajustando-se às faixas etárias e às condições das crianças" (SANTA CATARINA, 1998). Tratando da rede analisada, em 2015 foi construído ${ }^{6}$ um documento intitulado Diretrizes e Bases Curriculares da Educação Infantil da Rede Municipal de Ensino de Criciúma, o qual defende que os professores devem aprimorar seus planejamentos e priorizar uma Educação Física crítica.

Nos propomos compreender as concepções de desenvolvimento humano que estão presentes nos objetivos da Educação Física na Educação Infantil nas instituições públicas

3 Os autores declaram não haver conflito de interesse.

4 Esta má interpretação ocorre porque "[...] muitos professores resumem sua ação a observar os seus alunos na quadra enquanto eles realizam atividades que eles mesmos escolheram" (MACHADO, 2010).

5 Capítulo I - Da composição de níveis escolares - Art. 21: I- educação básica, formada pela educação infantil, ensino Fundamental e ensino médio (LDB/96).

6 Construído com os professores da Rede Municipal de Criciúma que atuam na Educação Infantil. 
de Criciúma. Para isto, delimitamos por objetivos específicos: conhecer os objetivos da Educação Física na Educação Infantil em Criciúma, analisar as concepções da Educação Física expressa nos objetivos dos professores e a partir das concepções de Educação Física analisadas, compreender as concepções de desenvolvimento humano vinculadas à Educação Física na Educação Infantil.

\section{METODOLOGIA}

A metodologia constitui-se de um estudo de campo. A pesquisa de campo procede à observação de fatos e fenômenos exatamente como ocorrem no real, à coleta de dados referentes aos mesmos e, finalmente, à análise e interpretação desses dados (FUZZI, 2010).

O presente trabalho é parte constituinte de uma pesquisa ampla, intitulada Educação Física e Escola: um filme da realidade da região carbonífera do Grupo de Pesquisa em Educação Física e Escola (GEPEFE) da Unesc, na qual uma das pesquisadoras foi bolsista de iniciação científica. Em 2015, iniciamos o subprojeto A Educação Física na Educação Infantil na Região Carbonífera, tendo por objetivo, analisar o estado da arte da Educação Física na Educação Infantil dessa região, com o intuito de constituir proposições de intervenção didático-metodológicas na perspectiva Histórico-cultural.

Entramos em contato com as secretarias de educação por meio de telefonemas e e-mails. Realizamos o levantamento dos dados das instituições de Educação Infantil de sete municípios pertencentes a AMREC (Associação da Região Carbonífera), sendo eles: Treviso, Siderópolis, Forquilhinha, Nova Veneza, Morro da Fumaça, Cocal do Sul e Criciúma.

Elaboramos uma entrevista como instrumento de coleta de dados, com perguntas referentes à formação dos professores, locais de trabalho, carga horária e quanto à sua práxis pedagógica. A proposta foi assistir à uma hora/aula do professor de Educação Física na Educação Infantil e realizar a entrevista elaborada pelo grupo, preenchendo os diários de campo para posteriores análises.

Compreendendo que esse artigo é um recorte de tal pesquisa, nos detemos na Rede Municipal de Criciúma, a qual é composta por sessenta e três instituições de Educação Infantil que possuem Educação Física na grade curricular. Consideramos ser um grande número de instituições no município e adotamos um cálculo amostral. Visitamos cinquenta e uma escolas. Atuavam nessas escolas, quarenta e oito professores de Educação Física, sendo que três destes trabalhavam em duas instituições do município.

Mediante ao exposto, apontamos a fundamentação teórica que utilizamos em nossas análises. Nos baseamos nas concepções de desenvolvimento e aprendizagem apresentadas por Fontana e Cruz (1997) na obra Psicologia e Trabalho Pedagógico; sobre as tendências pedagógicas nos apoiamos na categorização de Libâneo (1998), no livro Democratização da escola pública: a pedagogia crítico-social dos conteúdos; e para as concepções da Educação Física, tratamos Darido (2003) com a obra: Educação Física na Escola: Questões e Reflexões. Em relação à Educação Física na Educação Infantil que queremos, nos norteamos pela proposta teórica metodológica Crítico-Superadora, organizada pelo Coletivo 
de Autores na obra Metodologia do Ensino de Educação Física (1992). Estes elementos se articulam de maneira dialética.

Passamos a discorrer sobre as teorias supracitadas, fazendo uma articulação inicial entre concepções de aprendizagem e desenvolvimento com as tendências educacionais e concepções de Educação Física. Logo após serão apresentados os objetivos da Educação Física na Educação Infantil em Criciúma, e suas devidas análises. Por fim, abordaremos a atividade principal da criança e a Educação Física na Educação Infantil.

\title{
As concepções de desenvolvimento e aprendizagem e as tendências pedagógicas da educação que permeiam as concepções de educação física
}

Buscamos elaborar "uma síntese, que possa se constituir num ponto de partida do debate das atuais correntes e tendências na teoria da educação brasileira" (GADOTTI, 1987, p.7). Compreendendo as concepções de desenvolvimento e aprendizagem e as tendências pedagógicas da educação, distinguimos os modelos de Educação Física que estão presentes nas instituições de Educação Infantil municipais da cidade de Criciúma.

Destacamos, que

\begin{abstract}
Analisar as principais características das tendências que permeiam o universo nacional no que diz respeito à temática da Educação Física escolar é fundamental, uma vez que a discussão destas questões com os professores é muito importante para que se explicitem os pressupostos pedagógicos que estão por trás da atividade do ensino, na busca da coerência entre o que se pensa e o que realmente se faz (DARIDO, 2003, p.12).
\end{abstract}

A preocupação com o estudo da criança é recente na história da humanidade, não existia antes do século XVII, pois a criança era companheira espontânea do adulto. O avanço das descobertas científicas tornou possível o prolongamento da vida e a diminuição da mortalidade infantil. Nessa época se iniciou o costume de levar crianças as escolas (FONTANA E CRUZ, 1997).

O termo escola surgiu com a Revolução Industrial, pois o maquinário e a divisão social do trabalho enfraqueceram o modelo antigo de educação familiar, o qual passou a ser insuficiente para atender a uma sociedade moderna e civilizada. No momento em que a família deixou de ser a única responsável pela educação dos filhos, a escola assumiu a responsabilidade pelos conhecimentos técnicos e científicos (CAMPOS, 2010).

Neste período, a democracia burguesa defendia a tese de que a marginalidade era resultado da ignorância e, portanto, a escola como dever do Estado e direito de todos precisava transformar os indivíduos da classe proletária, em cidadãos. Para isso, o processo de ensino-aprendizagem tinha como centro o professor, que possuía a função de transmitir seus conhecimentos para os alunos (SAVIANI, 2009).

Portanto, 


\begin{abstract}
Quando pensamos na complexidade de tudo o que ocorre na escola, percebemos a multiplicidade de relações em que está envolvido o "ensinar e aprender". Relações econômicas e materiais, relações sociais e institucionais, relações entre conteúdos e métodos de ensino, crenças, concepções, teorias (FONTANA E CRUZ, 1997, p.4).
\end{abstract}

Quando tratamos de crianças, "as ideias que temos sobre aprendizagem quase sempre se relacionam ao seu desenvolvimento, já que habitualmente admitimos que aprendizagem e desenvolvimento são processos, de alguma forma, inter-relacionados" (FONTANA E CRUZ, 1997, p.5).

Discutiremos sobre as concepções de desenvolvimento humano e as tendências educacionais que norteiam os objetivos da Educação Física. Sistematizamos o trabalho por sessões: abordagem Inatista Maturacionista: fatores hereditários e de maturação; Abordagem Comportamentalista: estímulo e resposta; Abordagem Piagetiana: aspectos afetivos e emocionais; Abordagem Histórico-cultural: desenvolvimento e aprendizagem caminham juntos.

\title{
Abordagem Inatista Maturacionista: fatores hereditários e de maturação
}

A abordagem inatista-maturacionista foi à primeira concepção de desenvolvimento humano a se destacar. Enfatiza que os fatores hereditários ou de maturação são mais importantes para o desenvolvimento da criança do que os fatores relacionados à aprendizagem e à experiência. Aponta que as aptidões individuais são biológicas e já estão determinadas quando a criança nasce. Assim, o papel do meio social é de permitir ou impedir que essas aptidões se manifestem (FONTANA E CRUZ, 1997).

Os estudos dentro da abordagem inatista-maturacionista sugerem a existência de um processo de maturação inerente às transformações do comportamento da criança, que estabelece escalas de desenvolvimento para comparar os comportamentos de uma criança com os comportamentos esperados, ou considerados "normais", para cada faixa etária. Não importa o lugar e a época que a criança viva ou as condições materiais e as possibilidades educacionais a que tenha acesso: a criança "normal" deve apresentar tais comportamentos (FONTANA E CRUZ, 1997).

Sob esta ótica, "quando dizemos que, para ensinar à criança uma coisa determinada, é preciso esperar que ela amadureça ou atinja uma certa idade, estamos subordinando a aprendizagem ao desenvolvimento" (FONTANA E CRUZ, 1997, p.5).

Das tendências liberais, a que está enraizada na abordagem inatista-maturacionista intitula-se Tendência Liberal Tradicional, em que o papel da escola "consiste na preparação intelectual e moral dos alunos para assumir sua posição na sociedade [...] O caminho cultural em direção ao saber é o mesmo para todos os alunos, desde que se esforcem" (LIBÂNEO, 1998, p.23). As Tendências Pedagógicas Liberais surgiram no século XIX, sob forte influência dos ideais da Revolução Francesa - igualdade, liberdade e fraternidade com a finalidade de justificar o sistema capitalista.

No âmbito da Educação Física, se destacam as concepções desenvolvimentista e saúde renovada. A concepção desenvolvimentista defende a ideia de "priorizar a aprendizagem 
do movimento, embora possam estar ocorrendo outras aprendizagens em decorrência da prática de habilidades motoras" (DARIDO, 2003, p.4). Os conteúdos devem obedecer uma sequência fundamentada no modelo de taxonomia do desenvolvimento motor.

Na concepção de saúde renovada, a comunidade científica busca elaborar alternativas que auxiliem na tentativa de reverter a elevada incidência de distúrbios orgânicos associados à falta de atividade física (DARIDO, 2003). A prática de atividade física se caracteriza como "importante atributo no desenvolvimento de atitudes, habilidades e hábitos que podem auxiliar na adoção de um estilo de vida ativo fisicamente na idade adulta" (DARIDO, 2003, p.18).

\section{Abordagem Comportamentalista: estímulo e resposta}

A abordagem comportamentalista pontua a influência de fatores externos, do ambiente e da experiência sobre o comportamento da criança. Parte do princípio de que as ações dos indivíduos são determinadas por suas relações com o meio em que se encontram. Embora o comportamento do homem difira dos animais em razão de um maior refinamento e complexidade, ambos podem ser explicados pelos mesmos princípios. Desta maneira, o comportamento é sempre uma resposta do organismo (humano ou animal) a algum estímulo presente no meio ambiente. Estímulo é toda e qualquer modificação do ambiente que pode ser captada pelo organismo por meio de sentidos (FONTANA E CRUZ, 1997).

Portanto, os processos e fatores internos ao indivíduo não são levados em conta e o desenvolvimento é explicado como decorrente da aprendizagem. Para os comportamentalistas, desenvolvimento e aprendizagem são coincidentes. O desenvolvimento é tomado como resultado das aprendizagens acumuladas no decorrer da vida do indivíduo. O ensino é organizado a partir da valorização do planejamento, da definição dos objetivos que se pretende atingir, da organização das sequências de atividades e da definição de reforçadores (FONTANA E CRUZ, 1997).

Balizada por estes princípios, surge a Tendência Liberal Tecnicista, tornando a educação subordinada à sociedade, tendo como função a preparação de recursos humanos - mão de obra para as indústrias (GADOTTI, 1987).

Na Educação Física essa concepção ficou conhecida como Esportivizada. Os professores buscavam ângulos e movimentos perfeitos, tomando os alunos como atletas, para que estes pudessem representar o país quando houvessem competições esportivas (DARIDO, 2003).

\section{Abordagem Piagetiana: aspectos afetivos e emocionais}

A abordagem piagetiana leva o nome de seu autor Jean Piaget (1896-1980), que se preocupou em descobrir como o ser humano elabora seus conhecimentos sobre a realidade. Buscou explicar a forma pela qual o homem atinge o conhecimento lógico-abstrato que o distingue das outras espécies animais (FONTANA E CRUZ, 1997). 
As relações entre o organismo e o meio são relações de troca, pelas quais o organismo adapta-se ao meio e, ao mesmo tempo, o assimila, de acordo com suas estruturas, num processo de equilibrações sucessivas entre assimilação (as coisas e os fatos do meio são inseridos em um sistema de relações e adquirem significação para o indivíduo) e acomodação (processo de modificação que se opera nas estruturas do pensamento do indivíduo) que conduzem a maneiras de agir e de pensar cada vez mais complexas e elaboradas (FONTANA E CRUZ, 1997).

Esses processos de equilibrações sucessivas apresentam estágios definidos, cada estágio se caracteriza por uma maneira típica de agir e de pensar e constitui uma forma particular de equilíbrio em relação ao meio. A criança passa de um estágio a outro de seu desenvolvimento cognitivo quando seus modos de agir e pensar mostram-se insuficientes para enfrentar os novos problemas que surgem em relação ao meio (FONTANA E CRUZ, 1997).

Em síntese, o desenvolvimento da criança depende de sua equilibração. A aprendizagem praticamente não interfere no desenvolvimento. Aquilo que a criança pode ou não aprender é determinado pelo nível de desenvolvimento de suas estruturas cognitivas. Tudo o que é transmitido pela criança sem que seja compatível com seu estágio de desenvolvimento cognitivo não é incorporado por ela (FONTANA E CRUZ, 1997).

Com base no que foi exposto, em meados do século XX, manifestou-se a Tendência Liberal Renovada Progressivista. O papel da escola passa a ser o de ordenar as necessidades individuais do meio social, experiências que devem satisfazer os interesses do aluno e as exigências sociais (LIBÂNEO, 1994). Esta tendência na especificidade da Educação Física se desmembra em outras duas concepções, sendo elas: psicomotricidade e construtivista.

A psicomotricidade, "aborda o fato de que a atividade motora está diretamente relacionada aos aspectos psicológicos (emocionais e cognitivos) do indivíduo" (BROUCO; DARIDO; 2003). Segundo Le Boulch (1992), a psicomotricidade se dá através de ações educativas de movimentos espontâneos e atitudes corporais da criança, proporcionando-Ihe uma imagem do corpo, contribuindo para a formação de sua personalidade. É uma prática pedagógica que visa o desenvolvimento integral da criança no processo de ensino-aprendizagem, favorecendo os aspectos físicos, mental, afetivo-emocional e sociocultural. Nega à Educação Física uma especificidade.

A concepção construtivista foi "influenciada pela psicomotricidade, tanto na busca da formação integral, com a inclusão das dimensões afetivas, cognitivas ao movimento humano, como na discussão sobre o papel da Educação Física na escola" (BROUCO; DARIDO; 2003). A intenção é "a construção do conhecimento a partir da interação do sujeito com o mundo, numa relação que extrapola o simples exercício de ensinar e aprender" (DARIDO, 2003, p.7).

\section{Abordagem Histórico-cultural: desenvolvimento e aprendizagem caminham juntos}

A abordagem histórico-cultural tem como principal autor Vigotski (1896-1934). Explica como se formaram, ao longo da história do homem, as características tipicamente 
humanas de seu comportamento e como elas se desenvolvem em cada indivíduo (FONTANA E CRUZ, 1997).

A distinção do homem de outras espécies é a sua vida em sociedade. A relação entre homem e o meio físico e social não é natural, é total e diretamente direcionada pela estimulação ambiental. Também não é uma relação de adaptação do organismo ao meio. O homem, pelo trabalho, transforma o meio produzindo cultura (FONTANA E CRUZ, 1997).

A relação entre homem e meio é sempre mediada por produtos culturais humanos, como o instrumento e o signo. A apropriação dos instrumentos e dos signos pelo indivíduo ocorre sempre na interação com o outro (FONTANA E CRUZ, 1997).

Toda função psicológica se desenvolve em dois planos: primeiro, no da relação entre indivíduos e, depois, no próprio indivíduo. O desenvolvimento é um processo de internalização de modos culturais de pensar e agir. Embora existam diferenças entre aprendizado e desenvolvimento, os dois caminham juntos. $\mathrm{O}$ aprendizado precede e impulsiona o desenvolvimento (FONTANA E CRUZ, 1997).

As tendências pedagógicas progressistas surgem na França a partir de 1968. No Brasil coincide com o início da abertura política e com a efervescência cultural (MOITA; QUEIROZ; 2007). Intitulam-se progressistas porque partem de uma análise crítica das realidades sociais e sustentam implicitamente as finalidades sociopolíticas da educação (LIBÂNEO, 1998). E se manifestam em três concepções: libertadora, libertária e crítico-social dos conteúdos.

A tendência progressista libertadora questiona a realidade das relações do homem com a natureza e com os outros homens. Se constitui em uma atividade em que professores e alunos, mediatizados pela realidade que aprendem e da qual extraem o conteúdo e a aprendizagem, atingem um nível de consciência dessa mesma realidade, a fim de nela atuarem, visando uma transformação social (LIBÂNEO, 1998).

A tendência progressista libertária busca exercer uma transformação na personalidade dos alunos em um sentido libertário e auto gestionário. A auto-gestão é o conteúdo e o método. Esta tendência pretende ser uma forma de resistência contra a burocracia como instrumento da ação dominadora do Estado, que tudo controla, retirando a autonomia (LIBÂNEO, 1998).

A tendência progressista crítico-social dos conteúdos defende que a difusão dos conteúdos é primordial. Tem por função dar um passo à frente no papel transformador da escola. A escola deve garantir a todos a apropriação dos conteúdos escolares básicos que tenham relevância na vida dos alunos. Consiste na preparação do aluno para o mundo adulto e suas contradições, fornecendo-lhe um instrumento, por meio da aquisição de conteúdos e da socialização, para uma participação ativa na democratização da sociedade (LIBÂNEO, 1998).

Na Educação Física as concepções que se encaixam a estas tendências são conhecidas como crítico-emancipatória e crítico-superadora.

A proposta crítico-emancipatória utiliza-se do esporte como tema central das suas discussões propondo uma transformação didático-pedagógica do esporte, por ser uma prática que reflete a organização da sociedade, reproduz o modelo vigente e reafirma o 
sistema classificatório e a coerção auto imposta que exclui e seleciona os indivíduos quanto as suas interações sociais (KUNZ, 2014).

Enfatiza o agir comunicativo, defendendo que o movimentar-se humano é uma forma de comunicação com o mundo. Visa a autonomia do sujeito, a capacidade de agir para transformar e indica que o indivíduo precisa ter contato com o conhecimento para adquirir a habilidade de questionar as suas possibilidades enquanto sujeito (BRACHT, 1999).

A proposta crítico-superadora trata a Educação Física como uma prática pedagógica, que "[...] no âmbito escolar, tematiza formas de atividades expressivas corporais como: jogo, esporte, dança, ginástica, formas estas que configuram uma área de conhecimento que podemos chamar de cultura corporal" (COLETIVO DE AUTORES, 1992, p.50).

Adere o termo cultura corporal como objeto de ensino da Educação Física. Aquilo que sustenta a expressão corporal como linguagem. E que compõe suas relações essenciais. Busca contemplar a totalidade da apreensão do conhecimento específico da Educação Física (COLETIVO DE AUTORES, 1992).

Propõe o trato pedagógico diretamente com o conhecimento científico. Enfatizando que é apropriando-se deste, que as crianças irão desenvolver as suas funções psíquicas superiores. E assim sair da sua zona de desenvolvimento real e ampliar o seu conhecimento sobre determinado objeto (COLETIVO DE AUTORES, 1992).

\section{Os objetivos da Educação Física na educação infantil em Criciúma}

Os objetivos da Educação Física na educação básica, por suas origens militares e médicas e por seu atrelamento aos mecanismos de manutenção do status quo vigente na história brasileira, se relacionam fortemente aos conceitos de corpo e movimento - aos seus aspectos fisiológicos e técnicos. Atualmente, a análise crítica e a busca de superação dessa concepção apontam a necessidade de que, se considere também as dimensões cultural, social, política e afetiva, presentes nos corpos que interagem e se movimentam como sujeitos (BRASIL, 1997).

De acordo com Fontana e Cruz (1997, p.70),

[...] não dá para considerar a prática como aplicação da teoria, nem a teoria como algo que se aplica à prática. A prática é a base da teoria (que também é uma produção humana de produção de conhecimento). E a teoria elaborada é uma reflexão organizada e sistematizada sobre aspectos da prática que nos ajudam a analisa-la, problematiza-la e redefini-la.

Assim podemos entender as teorias pedagógicas como "lentes através das quais olhamos a prática pedagógica e que nos ajudam a compreendê-la" (idem). Por isso, nesse tópico abordaremos os elementos citados por quarenta e oito professores que atuam na Educação Física na Educação Infantil em Criciúma, buscando compreender como se expressam as concepções de desenvolvimento humano e as concepções de Educação Física 
nos objetivos que estes professores apresentam para ratificar a importância da disciplina e orientar as suas práticas em aula.

\section{Análise das respostas dos professores: a Educação Física na educação infantil que temos}

Na fala de $27 \%$ dos professores - treze respostas - aparecem como objetivo da Educação Física na Educação Infantil características de duas propostas no campo da Educação Física, a Desenvolvimentista e a Saúde renovada.

Evidenciamos a concepção desenvolvimentista na fala do professor $A^{7}$, o qual acredita que o objetivo da Educação Física na Educação Infantil é o "Desenvolvimento motor da criança em geral e específico de cada turma". Nesse viés, as aulas de Educação Física escolar servem para que os alunos tenham a possibilidade de vivenciar movimentos de acordo com seus níveis de maturação.

Na fala do professor B, encontramos indícios da concepção saúde renovada, quando ele diz que o objetivo da Educação Física na Educação Infantil é "ampliar o acervo motor da criança. Infância com caráter introspectivo, expor e ampliar as vivências da criança, essa é a função da Educação Física. Hábito da atividade física começa aqui". Nesse sentido, as aulas giram em torno da aptidão física relacionada à saúde, para estimular os alunos a criarem o hábito do estilo de vida ativo.

Em relação a concepção de desenvolvimento humano, estes professores entendem o desenvolvimento infantil de acordo a abordagem inatista maturacionista, o qual atribui um papel central a fatores hereditários e de maturação no desenvolvimento da criança (FONTANA E CRUZ, 1997). Essa tese está presente na concepção desenvolvimentista, quando se trata de oportunizar aos alunos o desenvolvimento motor de acordo com seus níveis de maturação. Na concepção Saúde renovada, quando se entende que a criança deve criar o hábito de vida ativa em relação com suas condições biológicas.

Outros 10,4\% dos professores - cinco respostas - compreendem a Educação Física na Educação Infantil de acordo com a concepção Esportivizada. Isto é visível a partir da fala do professor C, o qual entende que o objetivo da Educação Física na Educação Infantil é "desenvolver desde o início as habilidades e valências físicas. Não só o lúdico, cantigas de roda, mas habilidades motoras, prepara para exercícios mais elaborados". Também na fala do professor D: "Personalidade, liderança, plantar a sementinha do esporte, um ser mais ativo". Se concretiza na fala do professor E: "Potencializar o desenvolvimento infantil".

Desse modo, o esporte adentra a escola associado a ideia de buscar um alto padrão de rendimento em um curto espaço de tempo, para formar um campeão, que seja cada vez mais eficiente. Assim, as aulas de Educação Física pairam sobre jogos pré-desportivos e a aproximação aos chamados esportes hegemônicos: futebol, voleibol, handebol e basquetebol.

7 Assumimos letras para diferenciar os professores e não revelar suas identidades. 
Em síntese, prevalece à abordagem Comportamentalista como concepção de desenvolvimento humano, em que um dado estímulo causará uma dada resposta. Esta abordagem aparece claramente na concepção esportivizada quando o esporte atua na formação da personalidade, da disciplina, potencializa os alunos, estimulando e moldando o comportamento dos alunos para atingir um melhor rendimento e também uma melhor disciplina durante as aulas.

A grande maioria dos professores, representando $52 \%$ da amostra - vinte e cinco respostas - entendem que o objetivo da Educação Física na Educação Infantil se relaciona aos princípios das concepções da Psicomotricidade e Construtivista.

É perceptível a referência da psicomotricidade na fala do professor F: "Que a criança perceba o meio que convive, que perceba o brincar, o correr". O professor $\mathrm{G}$, acredita que seja o "desenvolvimento das capacidades motoras, cognitivas, prepara para a alfabetização através do movimento". O professor $\mathrm{H}$ elenca algumas características: "O autoconhecimento da criança, tempo, localização, paciência da criança". Nessa concepção, as aulas de Educação Física se estruturam na aprendizagem por meio do movimento, com a finalidade de desenvolver a coordenação motora, a lateralidade, direcionalidade, esquema corporal, ações e emoções. O objetivo se centra no auxílio e preparo da criança para as demais atividades pedagógicas.

Quanto à proposta construtivista, o professor I cita que o objetivo da Educação Física na Educação Infantil é "desenvolver as habilidades motoras, integração, interagir com a turma. Desenvolvimento intelectual também. Desenvolvimento motor, recreação, socialização". O professor J explicita em sua fala outros elementos que compõem a proposta construtivista, em que o "aprendizado ocorre através da ludicidade". A organização da aula de Educação Física então, passa a ser norteada por jogos e brincadeiras, dos mais simples aos mais complexos, desenvolvendo o conhecimento do aluno de acordo com sua interação com o meio.

Nesse sentido, se adequam a abordagem de desenvolvimento humano Piagetiana, em que a criança pensa sobre as coisas e estabelece relações entre elas. A abordagem piagetiana fica explícita na Psicomotricidade e no Construtivismo, quando defende que a inteligência do indivíduo se dá pela incorporação dos dados da experiência e conduz as modificações no funcionamento cognitivo.

Os 10,4\% restantes - cinco respostas - assumem o objetivo da Educação Física na Educação Infantil de acordo com as propostas críticas referentes à Educação Física, concepção crítico emancipatória e crítico superadora.

Com a fala do professor $\mathrm{K}$, percebemos indícios da proposta emancipatória na ideia da "formação do cidadão humano, voltado para a consciência do movimento corporal", relacionado ao conceito de "se-movimentar". Também se evidencia nas aulas de Educação Física regidas por problematizações, buscando o agir comunicativo dos alunos.

$\mathrm{Na}$ fala do professor $\mathrm{L}$, percebemos elementos da proposta superadora: "Colaborar para o desenvolvimento humano da criança proporcionando-lhes as habilidades e os conhecimentos das atividades da cultura corporal". O professor M diz que o objetivo da Educação Física na Educação Infantil é o de "criar um ser social, desenvolvimento do ser 
social". Aqui, os planejamentos das aulas de Educação Física são organizados por temas, que expressam o processo lógico e histórico da cultura corporal. Tomados em espiralidade, buscam a superação das diferenças da luta de classes, para que o conhecimento científico sistematizado esteja ao alcance de todos (COLETIVO DE AUTORES, 1992).

Mediante ao exposto, estes professores adotam a abordagem Histórico-cultural como perspectiva de desenvolvimento humano, em que o ser humano é tomado como um ser ontologicamente social, sendo que aprendizagem e desenvolvimento caminham juntos. Esta ideia central está presente na concepção crítico-emancipatória, quando assume que este ser social deve ser capaz de refletir e dialogar sobre a sociedade que está inserido. E também se faz presente na crítico-superadora, quando a mesma defende que este ser deve se compreender enquanto sujeito da sociedade para que possa questionar e criticar as diferenças de classe, na busca pela socialização dos meios de produção e o fim da exploração do homem pelo homem.

\section{A atividade principal da criança e a Educação Física na educação infantil: a transforma- ção que queremos}

Apontamos que não há um consenso nas concepções de Educação Física e de desenvolvimento humano que regem as aulas de Educação Física na Educação Infantil na Rede Municipal de Criciúma. Podemos, no entanto, considerar alguns motivos que incidem sobre isso, como a diferenciação existente entre as formações iniciais nos cursos de graduação, as condições de trabalho dos professores, a questão de agregar mais de uma função e/ou maior carga horária para aumentar a renda familiar, a falta de condições financeiras para realizar cursos de formação continuada e especializações, entre outros.

Pretendemos com este estudo "instigar o professor a eleger, para a sua prática, aquela perspectiva que responde às exigências atuais do processo de construção da qualidade pedagógica da escola pública brasileira" (COLETIVO DE AUTORES, 1992, p. 23). Por isso, destacamos que 89,6 \% - que totalizam quarenta e três professores - não utilizam como concepção de desenvolvimento humano a teoria histórico-cultural. Apenas 10,4\% - que representam cinco professores - utilizam essa concepção de desenvolvimento e aprendizagem como elemento norteador de seus planejamentos.

Mas qual o problema que está colocado diante disso? A teoria histórico-cultural é a base de formação humana que legitima a Proposta Curricular do Estado de Santa Catarina (2014), a Proposta Curricular da Rede Municipal de Criciúma (2008) e as Diretrizes Curriculares da Educação Infantil da Rede Municipal de Ensino de Criciúma (2016). Ou seja, os principais documentos que regulamentam a Educação Física na Educação Infantil do município, afirmam essa teoria como base teórica.

Agregado a isso, acreditamos que a teoria histórico-cultural compreende o desenvolvimento humano em sua plenitude e que, portanto, possibilita uma melhor organização didático-metodológica. 
Quando nos confrontamos com 89,6\% de respostas dos professores de Educação Física da Rede de Educação Infantil de Criciúma contrárias a concepção de desenvolvimento que rege os documentos, percebemos as limitações teóricas que implicam em suas práxis cotidianas.

Por isso, com o objetivo de avançarmos na construção da Educação Física na Educação Infantil pautada em uma abordagem histórico-cultural, defendemos a perspectiva que o ser humano se desenvolve em atividade. Em cada período da vida o ser humano possui uma atividade guia de seu desenvolvimento, ao qual denominamos atividade principal (LEONTIEV, 1978).

Chamamos atividade principal aquela em conexão com a qual ocorrem as mais importantes mudanças no desenvolvimento psíquico da criança e dentro do qual se desenvolvem processos psíquicos que preparam o caminho da transição da criança para um novo e mais elevado nível de desenvolvimento (LEONTIEV, 2014, p.122).

Na idade pré-escolar, Leontiev (1978) aponta que a atividade que realiza a relação criança/mundo, no sentido de permitir a máxima apropriação das produções culturais historicamente elaboradas, é a atividade de jogo (NASCIMENTO; DANTAS; 2009). $\mathrm{Na}$ atividade de jogo, "o mais importante não é o prazer que a criança sente ao jogar, mas a utilidade objetiva e o significado objetivo do jogo" (VIGOTSKI, 2014, p.79-80). Pois o jogo é uma atividade em que se reconstroem, sem fins utilitários diretos, as relações sociais (ELKONIN, 2009).

Diante disso, ao discutir as possibilidades do jogo, delimitamos ao professor de Educação Física a "ação de organizar os materiais e conhecimentos sobre determinado tema para serem apropriados pelas crianças. A criança, dessa forma, terá acesso à significação dos objetos culturais pela mediação do educador" (NASCIMENTO; DANTAS; 2009, p.301). Portanto, a importância do professor de Educação Física na Educação Infantil se dá na sua formação e qualificação para este trabalho.

Sabemos, no entanto, que para construirmos uma Educação Física na Educação Infantil organizada a partir da sua atividade principal, precisamos possibilitar aos professores o acesso ao conhecimento mais elaborado sobre o tema. Ressaltamos, portanto, que o grande desafio é "somar os vários esforços e evitar a enorme dispersão de energia dos próprios educadores, dividida em numerosas entidades, sem articulação por não possuírem uma base gnosiológica-política comum" (GARCIA apud GADOTTI, 1987, p.15).

Entendendo que "a verdadeira educação consiste em despertar na criança aquilo que ela já tem em si, ajudá-la a desenvolvê-lo e orientar seu desenvolvimento em determinada direção" (VIGOTSKI, 2014, p.61), vislumbramos proporcionar as nossas crianças que desenvolvam suas funções psicológicas superiores e vivenciem o máximo de possibilidades nas aulas de Educação Física, se apropriando da cultura corporal. 


\section{REFERÊNCIAS}

BRACHT, Valter. A constituição das teorias pedagógicas da educação física. Caderno CEDES, Campinas, ano XIX, 48, p. 69-88. ago. 1999.

BRASIL. Lei de Diretrizes e Bases da Educação Nacional. Lei no 9.394/96, de 20 de dezembro de 1996 estabelece as diretrizes da Educação Nacional. Brasília: Ministério da Educação, 1996.

BRASIL. Parâmetros Curriculares Nacionais: Educação Física. Brasília: MEC/SEF, 1997.

BROUCO, Gisely Rodrigues; DARIDO, Suraya Cristina. As diferentes tendências pedagógicas da Educação Física escolar e o último concurso para professores da Rede Pública Estadual do Paraná. Londrina: LETPEF (Laboratório de Estudos e trabalhos pedagógicos em Educação Física), 2003.

CAMPOS, Alexandra Resende. Família e escola: um olhar histórico sobre as origens dessa relação no contexto educacional brasileiro. Programa de Pós Graduação em Educação - UFF (Universidade Federal Fluminense): Niterói, 2010.

COLETIVO DE AUTORES. Metodologia do Ensino de Educação Física. São Paulo: Martins, 1992.

CRICIÚMA. Diretrizes Curriculares da Educação Infantil da Rede Municipal de Ensino de Criciúma: a criança como protagonista da aprendizagem. Prefeitura Municipal: Secretaria da Educação, 2016.

DARIDO, Suraya Cristina. Educação Física na Escola: Questões e Reflexões. Rio de Janeiro: Guanabara Koogan S. A., 2003.

ELKONIN, Daniil B. Psicologia do Jogo. $2^{\text {a }}$ ed. São Paulo: Martins Fontes, 2009.

FONTANA, Roseli; CRUZ, Maria Nazaré. Psicologia e trabalho pedagógico. São Paulo: Atual, 1997.

FUZZI, Ludmila Pena. O que é a pesquisa de campo? Disponível em: < http:// profludfuzzimetodologia.blogspot.com.br/2010/03/o-que-e-pesquisa-de-campo.html > Acesso em 13 de set. de 2016.

GADOTTI, Moacir. Pensamento pedagógico brasileiro. São Paulo: Ática S. A., 1987.

KUNZ, Elenor. Transformação didático pedagógica do esporte. 8ª ed. Ijuí: Unijuí, 2014.

LE BOULCH, Jean. O desenvolvimento psicomotor. Porto Alegre: Artmed, 1992.

LEONTIEV, Alexei N. Os princípios psicológicos da brincadeira pré-escolar. In: VYGOTSKI, Lev S.; LURIA, Alexander R.; LEONTIEV, Alexei; Linguagem, desenvolvimento e aprendizagem. 12. ed. São Paulo: Ícone, 2014. p. 119-142.

. O desenvolvimento do psiquismo. Lisboa: Livros Horizonte, 1978.

LIBÂNEO, José Carlos. Democratização da escola pública: a pedagogia crítico-social dos conteúdos. $15^{\mathrm{a}}$ ed. São Paulo: Loyola, 1998.

. Didática. São Paulo: Cortez, 1994.

MACHADO, Thiago da Silva (org.). As práticas de desinvestimento pedagógico na Educação Física escolar. Revista Movimento: Porto Alegre, v. 16, n. 02, p. 129-147, abril/junho de 2010. 
MOITA, Filomena Maria Gonçalvez da Silva Cordeiro; QUEIROZ, Cecília Telma Alves Pontes. Fundamentos sócio-filosóficos da educação. Campina Grande/Natal: UEPB/ UFRN, 2007.

NASCIMENTO, Carolina Picchetti; DANTAS, Luiz Eduardo Pinto Bastos Tourinho. O desenvolvimento histórico-cultural da criança nas aulas de Educação Física: possibilidades de trabalho a partir da atividade principal e dos temas. Rev. Bras. Cienc. Esporte, Campinas, v. 31, n. 1, p. 147-161, setembro 2009.

PASQUALINI, Juliana Campregher. Contribuições da Psicologia Histórico-Cultural para a educação escolar de crianças de 0 a 6 anos: desenvolvimento infantil e ensino em Vigotski, Leontiev e Elkonin. Disssertação (mestrado) - FAPESP - Fundação de Amparo à Pesquisa do Estado de São Paulo, Araraquara, 2006.

SANTA CATARINA, Governo do Estado. Lei complementar $\mathbf{n}^{\mathbf{0}} \mathbf{1 7 0}$, de 07 de agosto de 1998, dispõe sobre o sistema estadual de educação. Diário Oficial: Florianópolis, 1998.

SAVIANI, Dermeval. Escola e Democracia: teorias da educação, curvatura da vara, onze teses sobre a educação política. 41 ed. Campinas, SP: Autores Associados, 2009.

VIGOTSKI, Lev S. Imaginação e criatividade na infância. São Paulo: WMF Martins Fontes, 2014.

Recebido em: Julho/2017

Aprovado em: Março/2018 